\title{
Adjuvant Chemotherapy of Locally Advanced Colon Cancer: Final Results of a Randomized Trial Comparing 5-Fluorouracil and Folinic Acid with Folfiri
}

\author{
Stephan Paschke ${ }^{a}$ Holger Hebart $^{b}$ Roland Goeb ${ }^{c} \quad$ Ludger Staib $^{d} \quad$ Ullrich Fleck $^{\mathrm{e}}$ \\ Doris Henne-Bruns ${ }^{a}$ Silvia Sander ${ }^{f}$ Karl-Heinrich Link ${ }^{g}$ Marko Kornmann ${ }^{a}$

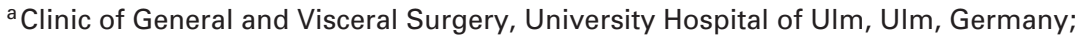 \\ ${ }^{\mathrm{b}}$ Center for Internal Medicine, Stauferklinikum, Schwäbisch Gmünd, Germany; \\ ${ }^{c}$ Department of General and Visceral Surgery, Katholisches Krankenhaus St. Johann Nepomuk, Erfurt, Deutschland; \\ ${ }^{\mathrm{d}}$ Department of General and Visceral Surgery, Städtisches Klinikum Esslingen, Esslingen, Germany; \\ e Department of General and Visceral Surgery, Krankenhaus Luckenwalde, Luckenwalde, Germany; \\ ${ }^{f}$ Institute of Epidemiology and Medical Biometry, University Hospital of Ulm, Ulm, Germany; \\ gDepartment of Surgery I, Asklepios Paulinen Klinik, Wiesbaden, Germany
}

\section{Keywords}

Chemotherapy · Colon cancer · Colorectal surgery ·

5-Fluorouracil · Irinotecan

\section{Summary}

Background: There is still the need to optimize adjuvant treatment of colon cancer (CC). Standard adjuvant chemotherapy using 5-fluorouracil (FU) and folinic acid (FA) was compared with a combination including irinotecan (Folfiri). The aim of the present report was to analyze overall survival (OS) after long-term follow-up, to summarize final recurrence rates and toxicity data, and to identify possible clinical and pathological factors associated with prognosis. Methods: Patients (CC stage Illb and III) were randomized to a 6-month treatment with FUFA or Folfiri. The trial was closed after 275 of 588 planned patients, 269 of which were included in the intention-totreat analysis. Results: 133 and 136 patients received FUFA and Folfiri, respectively. Adjuvant therapy was not completed for 16 FUFA (12.0\%) and 44 Folfiri (32.4\%) patients. Toxicities grade III and IV were observed in 17 $(12.8 \%)$ patients treated with FUFA and in 50 (36.8\%) patients treated with Folfiri. Recurrences occurred in 46 of $133(34.6 \%)$ and in 47 of $136(34.6 \%)$ patients who received FUFA and Folfiri, respectively. 5-year OS rates were $69.9 \%$ (95\% confidence interval (Cl): 61.2-77.1) for FUFA and $72.7 \%(95 \% \mathrm{Cl}$ : 63.9-79.8) for Folfiri. OS was associated with tumor grading ( $1 \& 2$ vs. 3), tumor sub- stage (II vs. Illa vs. IIlb vs. IIIc), and tumor location (left vs. right colon). Conclusion: Folfiri cannot be generally recommended for adjuvant chemotherapy of CC. Besides tumor grading and sub-staging, prognosis of CC may depend on tumor location. Left-sided tumors had a significantly better prognosis irrespective of treatment.

(c) 2018 S. Karger AG, Basel

\section{Introduction}

5-Fluorouracil(FU)-based adjuvant treatment of colon cancer (CC) was established more than 3 decades ago [1]. Its administration in lymph node-positive CC (Union for International Cancer Control (UICC) stage III) was estimated to reduce the relative risk of death by $26 \%$ compared to surgery alone [2]. Modulation of FU using folinic acid (FA) further improved its benefit [3], while modulation using levamisole was judged to be ineffective $[4,5]$. Several trials focusing on the duration of treatment revealed that 6-8 months may be as effective as 12 months $[5,6]$. Therefore, a 6-month adjuvant treatment using FU and FA was recommended as standard adjuvant treatment of UICC III CC in Germany [7].

Based on the increased response rates of combining FUFA with irinotecan or oxaliplatin and their almost equivalent efficacy in metastasized disease, both combinations were consequently evaluated for adjuvant treatment [8]. Two key trials investigating the efficacy of combining FUFA with oxaliplatin (Folfox) demonstrated improved 5- and 6-year overall survival (OS) rates by 2.7 and 4.4

\section{KARGER}

() 2018 S. Karger AG, Basel
Prof. Marko Kornmann, M.D 
points of percentage, respectively $[9,10]$. Several phase III trials were also launched to evaluate the combination of FUFA and irinotecan (Folfiri). In contrast to its efficacy in stage IV disease, the results of the adjuvant phase III trials never revealed a beneficial effect for Folfiri in stage III CC [11-13].

With the knowledge of the results of the largest German adjuvant trial in CC in mind [3], we designed a randomized phase III multicenter trial with the aim to improve OS in locally advanced CC. Standard adjuvant FUFA treatment was intensified by addition of irinotecan. Statistical estimation resulted in a sample size of 294 evaluable patients per treatment arm. Among other secondary endpoints, paraffin-embedded primary tumor tissue was prospectively collected to assess the effect of various biomarkers on adjuvant treatment $[14,15]$. Positive preliminary reports about a beneficial effect of Folfox [16] and rather disappointing preliminary reports about Folfiri [11-13] dramatically slowed down the recruitment of our trial. Consequently, this prompted the steering committee of our study group to close the trial after a recruitment of a total of 275 patients ( $47 \%$ of the estimated number of evaluable patients). The aim of the present report was to analyze OS after 5 years of follow-up for all patients, to summarize final recurrence rates and toxicity data, and to identify possible clinical and pathological factors associated with prognosis.

\section{Patients and Methods}

\section{Ethics}

The German 'Research Group Oncology of Gastrointestinal Tumors' (FOGT) designed a prospective randomized trial (FOGT 4) to optimize adjuvant treatment of CC complying with good clinical practice rules and respecting the Helsinki Declaration (updated 2000) to improve adjuvant treatment of locally advanced CC. The study was approved by the Ethics Committees of the University of Ulm (\#72/2001) and the Landesärztekammer Hessen (\#1271/2002). The trial was registered at the German Cancer Society and the Federal Institute for Drugs and Medical Devices (BfArM, \#4019926) and supervised by an independent study monitor.

\section{Eligibility Criteria}

Patients had a medical history, physical examination, electrocardiography, colonoscopy, complete blood cell count, and chemistry, including liver and renal function parameters and carcinoembryonic antigen (CEA). Distant metastases were excluded by abdominal ultrasound, chest X-ray, and intraoperative liver palpation. Computed tomography (CT) or magnetic resonance tomography scans were optional. Eligibility was defined as potentially curative en-bloc resection $\left(\mathrm{R}_{0}\right)$ of an adenocarcinoma of the colon with a lower tumor edge of at least $16 \mathrm{~cm}$ from the anal verge, a pathologic UICC stage II (pT4pN0cM0) or III (pT1-4pNposcM0) with examination of at least 12 lymph nodes, a white blood count $\geq 3,000 / \mu \mathrm{l}$, a neutrophil count $\geq 2,000 / \mu \mathrm{l}$, a platelet count $\geq 100,000 / \mu \mathrm{l}$, renal and liver function scores not exceeding more than 1.5-fold of upper normal levels, a Karnofsky index $>70 \%$ (Eastern Cooperative Oncology Group performance status of 0 or 1 ), age $\geq 18$ years, and written informed consent. Ineligible were patients not fulfilling these criteria or having a history of cancer, except for adequately treated superficial basal or squamous cell skin cancer or in situ carcinoma of the cervix, those with a history of previous radioor chemotherapy, pregnant or nursing women, those having severe concomitant diseases limiting life expectancy or not allowing chemotherapy, and those with social conditions not allowing a 5-year follow-up.

\section{Surgical and Pathological Procedures}

Procedures for conventional colonic resections were described in detail in the protocol and had to be performed according to the standards recommended by the German Cancer Society [17]. Laparoscopic resections were not allowed. For pathological workup, the examination of at least 12 lymph nodes was required. $\mathrm{R}_{0}$ was defined as complete resection to all directions without limit $(0$ $\mathrm{mm})$. The 5 th version of the UICC/TNM classification was used to document the pathological staging [18].

\section{Stratification and Randomization Procedures}

Enrollment of participants was performed by the participating FOGT members in their institutions. After checking inclusion and exclusion criteria, patients were registered by a phone call at the central FOGT office (European Medical Trial Support GmbH, Ulm, Germany). Patients were then stratified according to center, pT (pT1/2 vs. pT3/4), and lymph node status (pN0 vs. pN1 vs. pN2), and randomized according to an allocation sequence generated by the Institute of Epidemiology and Medical Biometry of the University of Ulm, Germany.

\section{Chemotherapy}

In a former trial [3], our group had proven that 12-month adjuvant treatment using FUFA + levamisole was superior to FU + levamisole. Levamisole was considered to be ineffective, and a treatment duration of 6 months was judged to be equivalent to 12 months [4-6]. Consequently, adjuvant treatment consisting of FUFA for 6 months was regarded as the standard. Therapy was scheduled to begin 14 days after surgery. FU $\left(450 \mathrm{mg} / \mathrm{m}^{2}\right)$ was administered as intravenous (i.v.) infusion for 60-120 min on day 1-5, and then administered 26 days after this loading course once weekly for 22 weeks (total of 26 weeks). If tolerated well, FU was increased to $500 \mathrm{mg} / \mathrm{m}^{2}$. FA (200 mg/m ${ }^{2}$; Rescuvolin ${ }^{\circledR}$, Medac GmbH, Hamburg, Germany) was given as an i.v. short infusion (10 min) prior to FU.

Experimental treatment consisted of i.v. Folfiri using a port system. Irinotecan $\left(80 \mathrm{mg} / \mathrm{m}^{2}\right)$ was administered as 60 -min infusion, followed by FA $(500 \mathrm{mg} /$ $\left.\mathrm{m}^{2}\right)$ for $120 \mathrm{~min}$ and 5 -FU $\left(2,000 \mathrm{mg} / \mathrm{m}^{2}\right)$ for $24 \mathrm{~h}$ using an automated pump system (Arbeitsgemeinschaft Internistische Onkologie (AIO) schedule) [12]. Prior to the administration of irinotecan, atropine $(0.25 \mathrm{mg}$ s.c.) was given. If tolerated, FU was increased to $2,200 \mathrm{mg} / \mathrm{m}^{2}$. One cycle consisted of 6 applications (d1, d8, d15, d22, d29, d36). The total treatment included 4 cycles repeated every 50 days.

\section{Adjustment of Chemotherapy}

For patients $>70$ years, the FU doses were initially reduced by $20 \%$. In case of grade III and IV toxicities, doses of FU and irinotecan were reduced by 20 and $40 \%$, respectively, and the treatment was discontinued until recovery from symptoms. FU doses were increased if no toxicity occurred up to 500 and 2,200 $\mathrm{mg} / \mathrm{m}^{2} 5$-FU in the standard and experimental arm, respectively. Irinotecan doses were not increased.

Toxicity

Toxicity was evaluated according to the National Cancer Institute common toxicity criteria (NCI-CTC, version 2.0). Doses were adjusted as described above, if necessary. Severe toxicities were reported to the BfArM.

\section{Follow-up}

Follow-up was performed 6-monthly for 5 years, including history, physical examination, white blood count, liver and renal function, CEA, and abdominal ultrasound. Chest X-ray was performed annually and colonoscopy after 2 and 5 years following surgery. Additional annual follow-up after 5 years was optional.

\section{Statistical Analysis and Endpoints}

The primary objective was to improve adjuvant chemotherapy of CC. Our hypothesis was that intensifying treatment using irinotecan in combination with FUFA may increase OS.

For sample size estimation the following assumptions were made: The 5 -year OS rate of FUFA was estimated to be $70 \%$ [3], and the 5-year OS rate of the more toxic Folfiri combination should be 10 percent points higher com- 


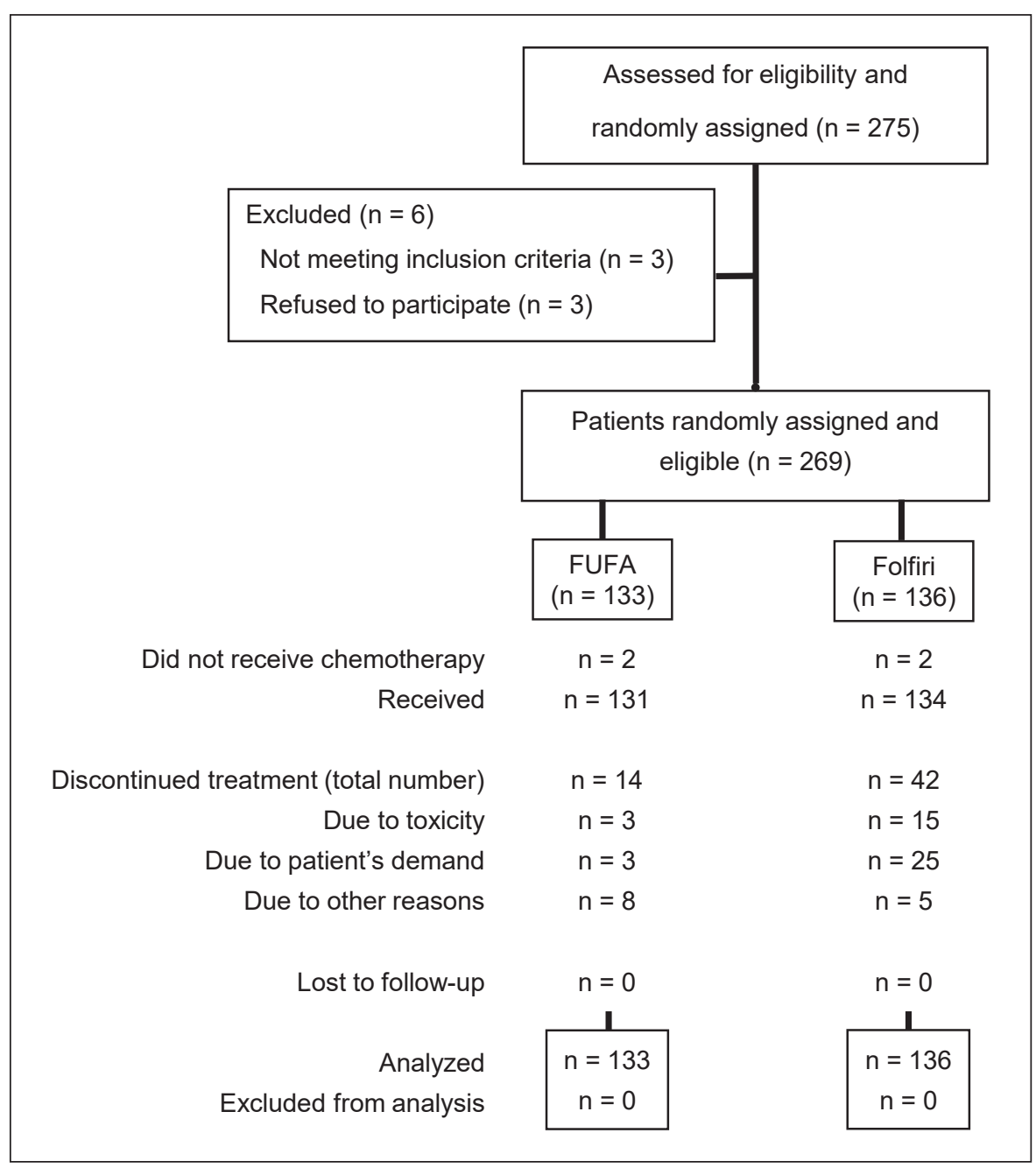

pared to FUFA. The power of the study was $80 \%$, and the level of significance was $2.5 \%$ (one-sided). This resulted in a sample size of 294 subjects per group.

Primary endpoint of the study was OS. OS was compared by log-rank testing for FUFA and Folfiri. Secondary endpoints were recurrence-free survival (RFS), toxicity, and treatment compliance. OS was computed from the start of chemotherapy or randomization for patients who did not receive any chemotherapy until death from any cause (events) or until the last observation date (censored observations). RFS was defined as time from start of chemotherapy or randomization for patients who did not receive any chemotherapy until diagnosis of any tumor recurrence or tumor-related death (events) or until death due to other reasons or last observation date (censored observations). Survival curves were generated by the Kaplan-Meier method. 5-year survival rates are shown in percent (\%) with $95 \%$ confidence intervals (CI). Toxicity rates were compared between the treatment arms using chi-square test. Stratified KaplanMeier analyses were performed to detect variables influencing RFS and OS and compared with the log-rank test. Statistical analysis was performed using SAS version 9.1 (SAS Institute Inc., Carry, NC, USA).

\section{Results}

\section{Patient Characteristics}

275 patients were registered. 6 (2.2\%) were regarded as dropouts due to rejection of informed consent $(n=3)$ or not meeting inclusion criteria (1 patient had a palliative segmental colon resec- tion, 1 UICC stage IV disease, and 1 a R1 resection). Of the remaining 269 patients, 133 and 136 were assigned to receive FUFA and Folfiri, respectively (fig. 1). Clinical and pathological characteristics of the 269 patients from 26 centers included in the intention-to-treat analysis are summarized in table 1.

\section{Adjuvant Treatment and Compliance}

Overall, 131 patients received FUFA and 134 Folfiri (fig. 1). Treatment started on January 15, 2002 for the first patient and finished on January 15, 2008 for the last patient. A total of 4 patients did not receive any adjuvant treatment due to death $(n=1)$, late postoperative complications $(\mathrm{n}=1)$ and pathologic blood chemistry $(\mathrm{n}=1)$ not allowing start of treatment within 3 months after surgery, and refusal of chemotherapy $(\mathrm{n}=1)$ (fig. 1).

A reduction of dose according to our protocol (see 'Adjustment of Chemotherapy' section above) was documented from the beginning or during treatment for 4 and 24 patients receiving FUFA and Folfiri, respectively. The reasons for dose reduction were toxicitybased in all 4 FUFA and in 22 Folfiri patients. Doses were reduced in 1 Folfiri patient due to age and in 1 patient due to other not specified reasons. Therefore, 127 of 133 patients (95.5\%) and 110 
Table 1. Patients' clinical and pathological characteristics

\begin{tabular}{|c|c|c|c|}
\hline \multirow[t]{2}{*}{ Patients } & \multicolumn{3}{|l|}{ Treatment } \\
\hline & FUFA & Folfiri & total \\
\hline$n$ & 133 & 136 & 269 \\
\hline \multicolumn{4}{|l|}{ Age, years } \\
\hline Median & 63.1 & 64.8 & 64.4 \\
\hline Range & $32.5-82.0$ & $35.6-80.0$ & $32.5-82.0$ \\
\hline$<70$ & 96 & 103 & 199 \\
\hline$\geq 70$ & 37 & 33 & 70 \\
\hline \multicolumn{4}{|l|}{ Sex } \\
\hline Male & 75 & 81 & 156 \\
\hline Female & 58 & 55 & 113 \\
\hline \multicolumn{4}{|l|}{ Tumor location } \\
\hline Left colon ${ }^{\mathrm{a}}$ & 65 & 76 & 141 \\
\hline Right colon ${ }^{\mathrm{b}}$ & 67 & 59 & 126 \\
\hline Unknown & 1 & 1 & 2 \\
\hline \multicolumn{4}{|l|}{ Tumor depth, $p T$} \\
\hline 1 & 0 & 0 & 0 \\
\hline 2 & 11 & 13 & 24 \\
\hline 3 & 79 & 95 & 174 \\
\hline 4 & 43 & 28 & 71 \\
\hline \multicolumn{4}{|l|}{ Lymph nodes, $p N$} \\
\hline 0 & 23 & 19 & 42 \\
\hline 1 & 71 & 78 & 149 \\
\hline 2 & 39 & 39 & 78 \\
\hline \multicolumn{4}{|l|}{ UICC stage } \\
\hline II & 23 & 19 & 42 \\
\hline $\mathrm{A}-\mathrm{T} 3 \mathrm{~N} 0$ & 2 & 4 & 6 \\
\hline B - T4 N0 & 21 & 15 & 36 \\
\hline III & 110 & 117 & 227 \\
\hline $\mathrm{A}-\mathrm{T} 1 / 2 \mathrm{~N} 1$ & 10 & 12 & 22 \\
\hline $\mathrm{B}-\mathrm{T} 3 / 4 \mathrm{~N} 1$ & 61 & 66 & 127 \\
\hline $\mathrm{C}-\mathrm{T} 1-4 \mathrm{~N} 2$ & 39 & 39 & 78 \\
\hline \multicolumn{4}{|l|}{ Grading, $G$} \\
\hline $1+2$ & 88 & 97 & 185 \\
\hline $3+4$ & 43 & 38 & 81 \\
\hline Unknown & 2 & 1 & 3 \\
\hline \multicolumn{4}{|l|}{ Karnofsky Index } \\
\hline $70<80$ & 3 & 7 & 10 \\
\hline $80<90$ & 33 & 36 & 69 \\
\hline $90<100$ & 49 & 50 & 99 \\
\hline 100 & 44 & 39 & 83 \\
\hline Missing & 4 & 4 & 8 \\
\hline
\end{tabular}

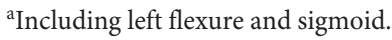

bincluding right flexure and transverse colon.

of 136 patients (82.1\%) received the dosage of FUFA and Folfiri, respectively, according to our protocol. Discontinuation of treatment was observed in 31 patients (11.5\%) within the first 6 weeks of treatment, in another $14(5.2 \%)$ within 3 months, in 7 (2.6\%) within 4.5 months, and in $7(2.6 \%)$ before 6 months. Treatment
Table 2. Reasons for treatment discontinuation

\begin{tabular}{llll}
\hline & \multicolumn{2}{l}{ Treatment } & \\
\cline { 2 - 4 } & $\begin{array}{l}\text { FUFA } \\
(\mathrm{N}=133)\end{array}$ & $\begin{array}{l}\text { Folfiri } \\
(\mathrm{N}=136)\end{array}$ & $\begin{array}{l}\text { Total } \\
(\mathrm{N}=269)\end{array}$ \\
\hline No chemotherapy at all & 2 & 2 & 4 \\
Patient's demand & 3 & 22 & 25 \\
Toxicity & 3 & 15 & 18 \\
Disease progression & 4 & 1 & 5 \\
Late surgical complication & 1 & - & 1 \\
Other reasons & 3 & 3 & 6 \\
Missing information & - & 1 & 1 \\
Total (\%) & $16(12.0)$ & $44(32.4)$ & $60(22.3)$ \\
\hline
\end{tabular}

Table 3. Toxicities grade III + IV according to NCI-CTC (version 2.0)

\begin{tabular}{llll}
\hline & \multicolumn{2}{l}{ Treatment } & \\
\cline { 2 - 4 } & $\begin{array}{l}\text { FUFA } \\
(\mathrm{N}=133)\end{array}$ & $\begin{array}{l}\text { Folfiri } \\
(\mathrm{N}=136)\end{array}$ & $\begin{array}{l}\text { Total } \\
(\mathrm{N}=269)\end{array}$ \\
\hline Patients with toxicities, n (\%) & $17(12.8)$ & $50(36.8)$ & $67(24.9)$ \\
\hline Type, n (\%) & & & \\
Leucopenia & $2(1.5)$ & $6(4.4)$ & $8(3.0)$ \\
Neutropenia & $1(0.8)$ & $5(3.7)$ & $6(2.2)$ \\
Thrombopenia & $1(0.8)$ & - & $1(0.4)$ \\
Mucositis & $3(2.3)$ & $3(2.2)$ & $6(2.2)$ \\
Nausea/Vomiting & $6(4.5)$ & $19(14.0)$ & $25(9.3)$ \\
Diarrhea & $10(7.5)$ & $34(25.0)$ & $44(16.4)$ \\
Skin & $1(0.8)$ & $1(0.7)$ & $2(0.7)$ \\
Others & $4(3.0)$ & $9(6.6)$ & $13(4.8)$ \\
\hline
\end{tabular}

${ }^{a}$ Number of documented toxicities $>$ grade II. Some patients suffered from more than one type of toxicity.

${ }^{b}$ Including constipation and infections as well as renal, pulmonal, cardiac toxicity.

was not started or discontinued in $16(12.0 \%)$ and 44 (32.4\%) of patients receiving FUFA and Folfiri, respectively.

In summary, the complete 6-month course of adjuvant chemotherapy was given to 209 patients $(76.6 \%)$, i.e. $88.0 \%$ (117/133) and $67.6 \%(92 / 136)$ of the FUFA and Folfiri group, respectively. 1 patient assigned to Folfiri received irinotecan for just one cycle, but FUFA for the complete 6 months. The reasons for discontinuation are summarized in table 2.

\section{Toxicity}

Grade III and IV toxicities occurred in 24.2\% (65/269) of all patients. More patients receiving Folfiri (36.0\%) than FUFA (12.0\%) were affected, which is attributable to more frequent gastrointestinal and hematological toxicities $(\mathrm{p}<0.001)$ (table 3$)$. As shown in table 2, toxicity-related discontinuation for Folfiri (15/136, 11.0\%) was also higher in comparison to FUFA (3/133, 2.3\%). 1 chemotherapy-related death occurred. During the second cycle of Folfiri 
Table 4. Location and frequency of tumor recurrence

\begin{tabular}{llll}
\hline & \multicolumn{2}{l}{ Treatment } & \\
\cline { 2 - 4 } & $\begin{array}{l}\text { FUFA } \\
(\mathrm{N}=133)\end{array}$ & $\begin{array}{l}\text { Folfiri } \\
(\mathrm{N}=136)\end{array}$ & $\begin{array}{l}\text { Total } \\
(\mathrm{N}=269)\end{array}$ \\
\hline $\begin{array}{l}\text { Total number of patients with tumor } \\
\text { recurrence, } \mathrm{n}(\%)\end{array}$ & $46(34.6)$ & $47(34.6)$ & $93(34.6)$ \\
\hline${\text { Local recurrence (only), } \mathrm{n}(\%)^{\mathrm{a}}}^{\mathrm{a}}$ & $5(3.8)$ & $1(0.7)$ & $6(2.2)$ \\
Local and distant recurrence, $\mathrm{n}(\%)$ & $9(6.8)$ & $5(3.7)$ & $14(5.2)$ \\
Distant recurrence (only), $\mathrm{n}(\%)$ & $32(24.1)$ & $41(30.1)$ & $73(27.1)$ \\
\hline Location (events) & & & \\
$\quad$ Liver & 20 & 21 & 41 \\
$\quad$ Lung & 9 & 16 & 25 \\
$\quad$ Peritoneum & 6 & 4 & 10 \\
$\quad$ Anastomosis & 5 & 1 & 6 \\
$\quad$ Lymph nodes & 8 & 10 & 18 \\
$\quad$ Bone & 1 & 2 & 3 \\
$\quad$ Other locations & 20 & 19 & 39 \\
\hline
\end{tabular}

${ }^{a}$ Local recurrence included anastomotic recurrence and extraluminal recurrence at the site of the former primary tumor.

${ }^{b}$ Due to the fact that some patients showed more than one location of recurrence the total number of metastatic sites is higher than the patient number.

treatment, the 59-year-old female patient developed leukopenia, neutropenia, and fever grade IV. After admission to hospital and medical treatment she died of a pulmonary embolism.

\section{Tumor Recurrence}

The median follow-up for all patients was 4.92 years (range: 0.0 8.1 years). Tumor recurrence was reported for 93 of 269 patients (34.6\%), i.e. $34.6 \%(46 / 133)$ and $34.6 \%$ (47/136) of FUFA and Folfiri patients, respectively. The locations of tumor recurrence are summarized in table 4. Distant metastases were reported for 73 patients (27.1\%). Tumor recurrence was reported for 1 patient who received FUFA for more than 5 years of follow-up. No difference in the pattern of recurrence was observed for the two treatment options. RFS was associated with $\mathrm{pT}, \mathrm{pN}$, UICC sub-stage, and tumor grading (table 5). Kaplan-Meier curves of RFS are shown in figure 2.

\section{Survival}

As of July 2015, 83 of 269 patients (30.9\%) had died, i.e. 46 of $133(34.6 \%)$ and 37 of $136(27.2 \%)$ receiving FUFA and Folfiri, respectively. Disease-specific (disease-related) deaths occurred in 32 of $133(24.1 \%)$ patients after FUFA treatment and in 28 of 136 (20.6\%) patients after Folfiri treatment. The total disease-specific death rate was $22.3 \%$ (60/269). 18 patients $(6.7 \%, 8$ Folfiri, 10 FUFA) died of other reasons, including 1 patient dying from treatment-related toxicity (Folfiri) and 6 from a secondary malignancy (1 Folfiri, 5 FUFA). The cause of death was unknown for 5 patients (1 Folfiri, 4 FUFA).
Table 5. 5-year rates of overall survival (OS) and recurrence-free survival (RFS) according to different risk factors

\begin{tabular}{|c|c|c|c|}
\hline \multirow[t]{2}{*}{ Risk factor } & \multirow[t]{2}{*}{$\mathrm{N}$} & \multicolumn{2}{|l|}{5 -year rates } \\
\hline & & OS, $\%(95 \% \mathrm{CI})$ & RFS, $\%(95 \% \mathrm{CI})$ \\
\hline \multicolumn{4}{|l|}{ Treatment } \\
\hline FUFA & 133 & $69.9(61.2-77.1)$ & $65.1(56.2-72.7)$ \\
\hline Folfiri & 136 & 72.7 (63.9-79.8) & $63.3(54.3-71.0)$ \\
\hline \multicolumn{4}{|l|}{ Sex } \\
\hline Male & 156 & $70.7(62.6-77.3)$ & $66.2(58.0-73.1)$ \\
\hline Female & 113 & $72.2(62.4-79.9)$ & $61.4(51.5-70.0)$ \\
\hline \multicolumn{4}{|l|}{ Age, years } \\
\hline$<60$ & 95 & $74.6(64.1-82.4)$ & $60.4(49.6-69.6)$ \\
\hline $60<70$ & 104 & $71.4(61.2-79.3)$ & $66.2(56.1-74.6)$ \\
\hline$\geq 70$ & 70 & $67.0(53.2-77.0)$ & $66.4(53.4-76.5)$ \\
\hline \multicolumn{4}{|l|}{$\mathrm{pT}$} \\
\hline 2 & 24 & 95.7 (72.9-99.4) & $91.7(70.6-97.8)$ \\
\hline 3 & 174 & $69.5(61.6-76.1)$ & $60.5(52.6-67.5)$ \\
\hline 4 & 71 & $67.0(54.6-76.8)$ & $63.4(50.7-73.6)$ \\
\hline \multicolumn{4}{|l|}{$\mathrm{pN}$} \\
\hline 0 & 42 & $83.1(67.7-91.5)$ & $85.3(70.1-93.1)$ \\
\hline 1 & 149 & $79.5(71.5-85.4)$ & $64.5(55.9-71.8)$ \\
\hline 2 & 78 & $49.4(37.6-60.1)$ & $52.2(40.3-62.8)$ \\
\hline \multicolumn{4}{|l|}{ UICC stage } \\
\hline II & 42 & $83.1(67.7-91.5)$ & $85.3(70.1-93.1)$ \\
\hline IIIa & 22 & $95.2(70.7-99.3)$ & $90.9(68.3-97.6)$ \\
\hline IIIb & 127 & $76.5(67.4-83.4)$ & $59.6(50.2-67.8)$ \\
\hline IIIc & 78 & $49.4(37.6-60.1)$ & $52.2(40.3-62.8)$ \\
\hline \multicolumn{4}{|c|}{ Tumor grading } \\
\hline $\mathrm{G} 1+2$ & 185 & $79.6(72.9-84.9)$ & $72.2(64.9-78.2)$ \\
\hline $\mathrm{G} 3+4$ & 81 & $52.5(40.5-63.2)$ & $45.6(34.2-56.4)$ \\
\hline \multicolumn{4}{|c|}{ Tumor location } \\
\hline Left & 141 & $79.5(71.4-85.5)$ & $68.3(59.7-75.4)$ \\
\hline Right & 126 & $62.6(53.2-70.7)$ & $59.8(50.4-68.0)$ \\
\hline \multicolumn{4}{|c|}{ Karnofsky index } \\
\hline $70<80$ & 10 & $70.0(32.9-89.2)$ & $68.6(30.5-88.7)$ \\
\hline $80<90$ & 69 & $68.6(55.4-78.6)$ & $52.1(39.5-63.3)$ \\
\hline $90<100$ & 99 & $69.0(58.3-77.4)$ & $64.9(54.4-73.6)$ \\
\hline 100 & 83 & $76.3(65.3-84.2)$ & $69.8(58.4-78.6)$ \\
\hline
\end{tabular}

OS after 3 years was $81.1 \%$ (95\% CI: $73.4-86.8 \%)$ and $85.5 \%$ (95\% CI: 78.2-90.5\%) for FUFA and Folfiri, respectively. No difference in OS was observed after 5 years of follow-up (table 5 , fig. 3 ). Univariate analysis revealed that OS was influenced by $\mathrm{pN}$, UICC sub-stage, tumor grading, and tumor location (table 5, fig. 3). The hazard ratios according to treatment and risk groups are shown in table 6.

RFS and OS are depicted according to treatment for UICC substage, tumor grading, and tumor location in table 7. Patients with UICC IIIc, low tumor grading, and left-sided tumor may benefit from Folfiri compared to FUFA.

Finally, multivariate analysis including treatment, gender, age, tumor location, UICC sub-stage, and tumor grading with backward elimination of variables revealed that only UICC sub-stage $(\mathrm{p}=0.0031)$ and tumor grading $(\mathrm{p}=0.0001)$ remained independent prognostic factors for OS. Tumor location was the last variable excluded $(\mathrm{p}=0.1245)$. 
Fig. 2. Recurrence-free survival according to $\mathbf{A}$ treatment (FUFA vs. Folfiri), B UICC sub-stage (II vs. IIIa vs. IIIb vs. IIIc), C tumor grading (G1 + 2 vs. G3), D tumor location (right vs. left).
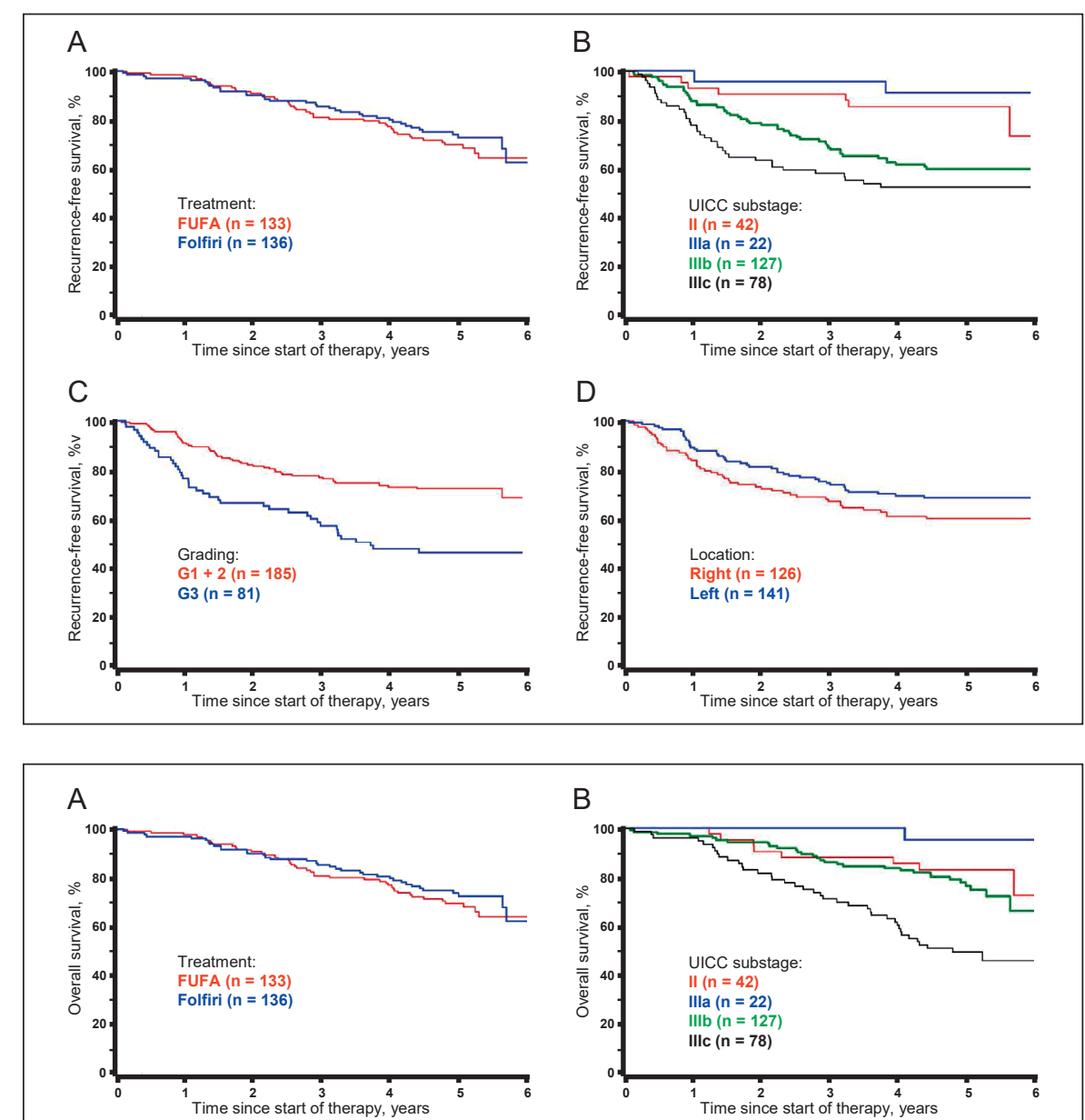

B

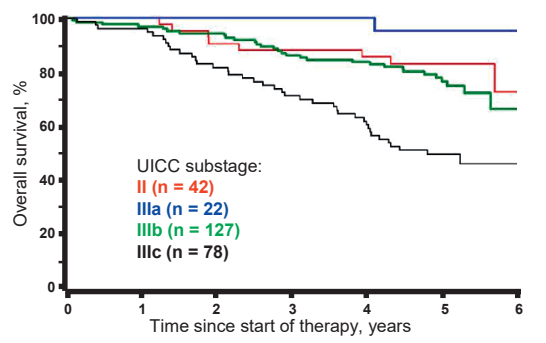

C

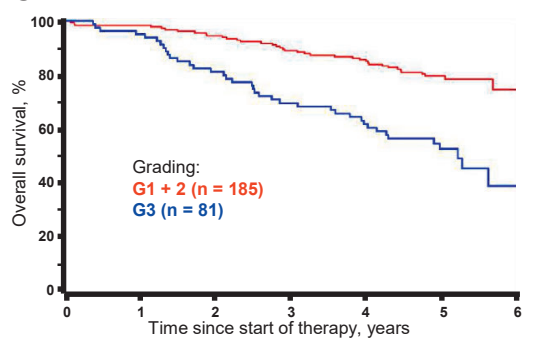

D

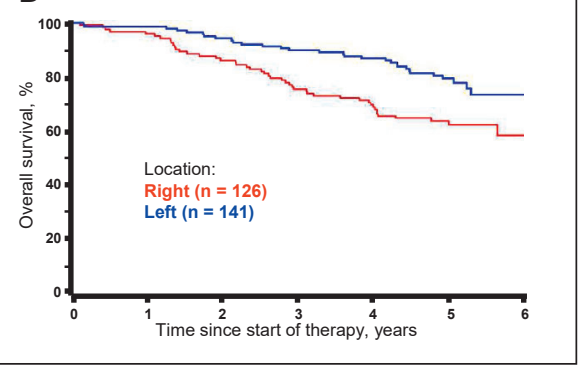

Fig. 3. Overall survival according to $\mathbf{A}$ treatment (FUFA vs. Folfiri), B UICC sub-stage (II vs. IIIa vs. IIIb vs. IIIc), C tumor grading (G1 + 2 vs. G3), D tumor location (right vs. left). in locally advanced CC [3], our study group planned the present trial using infusional $\mathrm{FU}$ and $\mathrm{FA}$ as the best standard treatment. The duration of adjuvant treatment was reduced from 12 to 6 months and oral levamisole was omitted as recommended at that time $[3,4]$. Our group chose irinotecan in combination with FUFA as intensified treatment because of its effectiveness in palliative treatment $[20,21]$. After an initial promising start, recruitment became more and more difficult based on preliminary reports from other adjuvant trials including oxaliplatin and irinotecan [11, 12, $16,23]$. This prompted the steering committee to close the trial after 6 years of recruitment, thus including 275 of 588 estimated patients.

This final evaluation revealed that the clinical and pathological characteristics were well balanced among the two treatment groups 
Table 6. Hazard ratios (HRs) according to treatment and risk groups

\begin{tabular}{|c|c|c|}
\hline Parameter & HR & 95\% HR confidence limits \\
\hline \multicolumn{3}{|l|}{ Treatment } \\
\hline FUFA & 1.0 & \\
\hline Folfiri & 0.9 & $0.6-1.3$ \\
\hline Age, per 1 year & 1.02 & $0.99-1.04$ \\
\hline \multicolumn{3}{|l|}{ Gender } \\
\hline Male & 1.0 & \\
\hline Female & 1.03 & $0.7-1.6$ \\
\hline \multicolumn{3}{|l|}{ pT } \\
\hline 2 & 1.0 & \\
\hline 3 & 9.5 & $1.3-68.4$ \\
\hline 4 & 10.5 & $1.4-77.2$ \\
\hline \multicolumn{3}{|l|}{$\mathrm{pN}$} \\
\hline 0 & 1.0 & \\
\hline 1 & 1.1 & $0.5-2.3$ \\
\hline 2 & 3.3 & $1.6-6.8$ \\
\hline \multicolumn{3}{|l|}{ UICC stage (II) } \\
\hline II & 1.0 & \\
\hline IIIa & 0.2 & $0.03-1.6$ \\
\hline IIIb & 1.3 & $0.6-2.7$ \\
\hline IIIc & 3.3 & $1.6-6.8$ \\
\hline \multicolumn{3}{|l|}{ Grading } \\
\hline $1+2$ & 1.0 & \\
\hline $3+4$ & 2.9 & $1.9-4.6$ \\
\hline \multicolumn{3}{|l|}{ Tumor location } \\
\hline Left & 1.0 & \\
\hline Right & 1.8 & $1.1-2.8$ \\
\hline
\end{tabular}

including 133 and 136 patients receiving FUFA and Folfiri, respectively. Adjuvant FUFA and Folfiri treatment was discontinued in 12 and $32 \%$ of the patients, respectively. The discontinuation rate in our former trial was $24 \%$ for the 12 -month FUFA treatment [3]. Nevertheless, $87 \%$ received at least the 6-month adjuvant FUFA treatment [3], resulting in a similar application rate for FUFA after 6 months. The knowledge that addition of irinotecan to FUFA may especially increase gastrointestinal toxicity $[20,21]$ prompted us to carefully adjust the dose of irinotecan within our Folfiri protocol in patients after colon resections. Other adjuvant Folfiri protocols used $125 \mathrm{mg} / \mathrm{m}^{2}$ irinotecan together with bolus FUFA (500 and 20 $\mathrm{mg} / \mathrm{m}^{2}$ ) weekly [11] or $185 \mathrm{mg} / \mathrm{m}^{2}$ in combination with FUFA (FA $200 \mathrm{mg} / \mathrm{m}^{2}$ as a 2-hour infusion, followed by bolus FU $400 \mathrm{mg} / \mathrm{m}^{2}$ and FU $600 \mathrm{mg} / \mathrm{m}^{2}$ continuous infusion over $22 \mathrm{~h}$ ) biweekly [12]. Overall, the weekly dose of irinotecan averaged 83 and $93 \mathrm{mg} / \mathrm{m}^{2}$, respectively $[11,12]$. Despite the fact that the dose of irinotecan (weekly $85 \mathrm{mg} / \mathrm{m}^{2}$ ) used in our trial was of similar 'weekly' intensity compared to the mentioned trials, the frequency of gastrointestinal toxicity was relatively high and resulted in a discontinuation rate of $32 \%$ for Folfiri.

Toxicities (III and IV) occurred in $12 \%$ of patients receiving infusional FUFA and mainly consisted of gastrointestinal symptoms (nausea/vomiting 5\%, diarrhea 8\%). FUFA was associated with toxicities grade III and IV in $13 \%$ of the patients in our former trial [3]. Irinotecan in combination with FUFA resulted in grade III and IV toxicities of $36 \%$ and mainly consisted of leukopenia/neutropenia (8\%) and gastrointestinal symptoms (nausea/vomiting $14 \%$ and diarrhea 25\%). Addition of irinotecan to bolus FUFA did not increase gastrointestinal toxicity but significantly increased leukopenia and neutropenia [11]. Addition of irinotecan to the biweekly infusional FUFA or to the weekly infusional AIO schedule increased hematological and gastrointestinal toxicity [12]. Compared to these trials, the overall observed grade III and IV toxicities for Folfiri were lower in frequency. However, the relatively high gastrointestinal toxicity may be attributable to the combination of irinotecan with the FUFA regimen (AIO) we used.

Despite more frequent side effects for Folfiri, the number of recurrences was equal for both treatment options examined. In the FOGT 1 adjuvant trial investigating the effect of modulation of FU by FA and interferon-alpha, patients with toxicity had a better prognosis [24]. In the present trial, the 5-year overall recurrence rate was $35 \%$ and in general comparable to other adjuvant trials investigating the effect of irinotecan [11-13]. As known from former adjuvant trials, recurrence rates strongly depend on the frequency of the included UICC sub-stages [24]. Therefore, a high proportion of patients with UICC stage IIIc (pTxpN2) and a low proportion of those with UICC stage IIIa $(\mathrm{pT} 1 / 2 \mathrm{pN} 1)$ can significantly influence recurrence rates and finally prognosis [25]. Consequently, this makes comparisons between observed recurrence rates of various trials even more difficult to interpret. Nevertheless, the observed distant recurrence rate of $32.3 \%$ (distant recurrences alone and distant with local recurrences) was absolutely in the range for locally advanced CC after standardized quality-controlled surgery [26].

As reported for other adjuvant phase III trials comparing FUFA with Folfiri in locally advanced CC [11-13], no beneficial effect of adding irinotecan to FUFA for patient prognosis was observed. However, 4 disease-specific deaths and 5 secondary malignancies less were reported for Folfiri. The 3- and 5-year OS was 4.4 and 2.8 points of percentage higher for Folfiri than for FUFA. Therefore, Folfiri may have some beneficial effects in the adjuvant treatment of locally advanced CC, considering that our trial was closed preliminarily with only $46 \%$ of planned patients recruited. In comparison, oxaliplatin in combination with FUFA improved 5- and 6-year OS by 2.7 and 4.4 points of percentage, respectively $[9,10]$.

Analysis of clinical and pathological factors influencing prognosis revealed that UICC sub-stages and tumor grading significantly influenced survival independent of adjuvant treatment. Both factors are well known independent prognostic factors in locally advanced CC receiving fluoropyrimidine-based adjuvant treatment [24]. Analysis of tumor location revealed that leftsided tumor location turned out with a favorable prognosis in comparison to right-sided independent of the adjuvant treatment used. We were unable to investigate the influence of tumor location and prognosis in our former adjuvant CC trial (FOGT 1) [3], because the exact primary tumor location was not docu-
Paschke/Hebart/Goeb/Staib/Fleck/Henne-Bruns/ Sander/Link/Kornmann 
Table 7. 5-year rates of overall survival (OS) and recurrence-free survival (RFS) according to treatment and risk factors

\begin{tabular}{|c|c|c|c|c|}
\hline \multirow[t]{2}{*}{ Risk factor } & \multirow[t]{2}{*}{ Treatment } & \multirow[t]{2}{*}{$\mathrm{N}$} & \multicolumn{2}{|l|}{5 -year rates } \\
\hline & & & OS, \% (95\% CI) & RFS, \% (95\% CI) \\
\hline \multicolumn{5}{|l|}{ UICC stage } \\
\hline \multirow[t]{2}{*}{ II } & FUFA & 23 & $82.2(59.2-92.9)$ & $82.2(59.2-92.9)$ \\
\hline & Folfiri & 19 & $84.2(58.7-94.6)$ & $89.5(64.1-97.3)$ \\
\hline \multirow[t]{2}{*}{ IIIa } & FUFA & 10 & $88.9(43.3-98.4)$ & $80.0(40.9-94.6)$ \\
\hline & Folfiri & 12 & $-{ }^{\mathrm{a}}$ & $-{ }^{\mathrm{a}}$ \\
\hline \multirow[t]{2}{*}{ IIIb } & FUFA & 61 & $78.1(65.2-86.7)$ & $65.5(51.7-76.2)$ \\
\hline & Folfiri & 66 & $74.7(60.3-84.5)$ & $54.0(40.6-65.6)$ \\
\hline \multirow[t]{2}{*}{ IIIc } & FUFA & 39 & $44.8(28.6-59.8)$ & $50.8(34.2-65.2)$ \\
\hline & Folfiri & 39 & $54.2(37.1-68.6)$ & $53.7(36.4-68.2)$ \\
\hline \multicolumn{5}{|c|}{ Tumor grading } \\
\hline \multirow[t]{2}{*}{$\mathrm{G} 1+2$} & FUFA & 88 & $77.6(67.1-85.1)$ & $71.9(61.1-80.2)$ \\
\hline & Folfiri & 97 & $81.5(71.9-88.1)$ & $72.4(62.0-80.5)$ \\
\hline $\mathrm{G} 3+4$ & FUFA & 43 & $55.1(39.0-68.5)$ & $51.4(35.1-65.5)$ \\
\hline G3 & Folfiri & 38 & $48.0(29.2-64.6)$ & \\
\hline \multicolumn{5}{|c|}{ Tumor location } \\
\hline \multirow{2}{*}{ Left } & FUFA & 65 & $75.8(63.0-84.7)$ & $65.1(52.0-75.5)$ \\
\hline & Folfiri & 76 & $82.8(71.6-89.9)$ & $71.1(59.2-80.1)$ \\
\hline \multirow[t]{2}{*}{ Right } & FUFA & 67 & $65.4(52.7-75.5)$ & $66.2(53.3-76.3)$ \\
\hline & Folfiri & 59 & $59.2(44.5-71.2)$ & $52.2(37.8-64.4)$ \\
\hline
\end{tabular}

${ }^{a}$ No events in this strata. mented. This might also be the reason why no association has been described between tumor location and outcome in older adjuvant trials. The observation that left-sided tumors display a more favorable prognosis than right-sided tumors is meanwhile a well-established fact and attributable to the exact documentation of tumor location within the colon allowing analysis [27, 28]. It was also reported for the data sets of adjuvant trials comparing FUFA with Folfiri [11, 12, 29]. Multivariate analysis of our data revealed that left-sided tumor location was associated with lower tumor grading and therefore did not turn out to be an independent prognostic factor. It has been described that rightsided tumors are often more undifferentiated compared to leftsided ones, show a higher T-stage, and may occur more often in older and female patients [30-32].

\section{Conclusion}

Despite premature closure of our trial, the results clearly demonstrate that addition of irinotecan to FUFA markedly increased toxicity. Similar to other trials, addition of irinotecan did neither reduce the frequency of recurrences nor enhance survival. Therefore, in general, Folfiri cannot be recommended for adjuvant chemotherapy of locally advanced CC. Future trials should aim to identify tumor subtypes according to clinical and pathological parameters as well as their molecular profile $[27,28$, 30-32], opening the chance to further individualize adjuvant treatment.

\section{Funding Sources}

This trial was financially supported by Medac GmbH, Hamburg, and Sanofi-Aventis GmbH, Frankfurt/M., Germany.

\section{Acknowledgements}

The authors would like to acknowledge all patients and participants, $\mathrm{U}$. Kemmer and U. Keller-Veith for data documentation, and M. Schatz (European Medical Trial Support GmbH, Ulm) for data monitoring.

Besides the authors of the manuscript, the following investigators in alphabetical order participated and recruited patients: L. Albrecht, Schorndorf; W. Baumann, Göppingen; M. Bausch, Lahnstein; J. Boese-Landgraf, Chemnitz; U. Bust, Sömmerda; H. Deneke, Schweinfurt; E. Eggers, Torgau; M. Esser, Bonn; W. Georgi, Niesky; L. Grimm, Geislingen; D. Hempel, Rehling; N. Heni, Biberach; E. Jäger, Frankfurt; B. Karn, Bad Liebenstein; E. Kettner, Magdeburg; G. Kleber, Aalen; H. Krause, Rinteln; M. Krych, München; R. Kunz, Berlin; E. Lotspeich, Ulm; D. Meissner, Chemnitz; S. Müller-Hagen, Hamburg; B. Otremba, Oldenburg; M. Schmelz, Bad Urach; D. Schmidt, Gera; T. Schulze, Dessau; G. Semmler, Rathenow; H. Tesch, Frankfurt; J. Vogt, Hanau.

\section{Disclosure Statement}

The authors declare no conflict of interest. 


\section{References}

1 Moertel CG, Fleming TR, Macdonald JS, Haller DG, Laurie JA, Goodman PJ, Ungerleider JS, Emerson WA, Tormey DC, Glick JH, Veeder MH, Mailliard JA: Levamisole and fluorouracil for adjuvant therapy of resected colon carcinoma. N Engl J Med 1990;322:352358

2 Gill S, Loprinzi CL, Sargent DJ, Thomé SD, Alberts SR, Haller DG, Benedetti J, Francini G, Shepherd LE, Fran cois Seitz J, Labianca R, Chen W, Cha SS, Heldebrant MP, Goldberg RM: Pooled analysis of fluorouracilbased adjuvant therapy for stage II and III colon cancer: who benefits and by how much? J Clin Oncol 2004;22:1797-1806.

3 Link KH, Kornmann M, Staib L, Redenbacher M, Kron M, Beger HG; Study Group Oncology of Gastrointestinal Tumors: Increase of survival benefit in advanced resectable colon cancer by extent of adjuvant treatment: results of a randomized trial comparing modulation of 5-FU + levamisole with folinic acid or with interferon-alpha. Ann Surg 2005;242:178-187.

4 QUASAR Collaborative Group: Comparison of fluorouracil with additional levamisole, higher-dose folinic acid, or both, as adjuvant chemotherapy for colorecta cancer: a randomised trial: Lancet 2000;355:15881596.

5 Haller DG, Catalano PJ, Macdonald JS, O’Rourke MA Frontiera MS, Jackson DV, Mayer RJ: Phase III study of fluorouracil, leucovorin, and levamisole in high-risk stage II and III colon cancer: final report of Intergroup 0089. J Clin Oncol 2005;23:8671-8678.

-6 O'Connell MJ, Laurie JA, Kahn M, Fitzgibbons RJ Jr, Erlichman C, Shepherd L, Moertel CG, Kocha WI, Pazdur R, Wieand HS, Rubin J, Vukov AM, Donohue JH, Krook JE, Figueredo A: Prospectively randomized trial of postoperative adjuvant chemotherapy in patients with high-risk colon cancer. J Clin Oncol 1998; 16:295-300

7 Junginger R, Hossfled DK, Sauer R, Hermanek P: Adjuvant therapy in patients with colorectal cancer. Deutsches Ärzteblatt 1999;96:A698-700.

8 Kornmann M, Link KH, Formentini A: Differences in colon and rectal cancer chemosensitivity. Colorectal cancer 2014;3:93-105.

9 André T, Boni C, Navarro M, Tabernero J, Hickish T, Topham C, Bonetti A, Clingan P, Bridgewater J, Rivera F, de Gramont A: Improved overall survival with oxaliplatin, fluorouracil, and leucovorin as adjuvant treatment in stage II or III colon cancer in the MOSAIC trial. J Clin Oncol 2009;27:3109-3116.

10 Yothers G, O’Connell MJ, Allegra CJ, Kuebler JP, Colangelo LH, Petrelli NJ, Wolmark N: Oxaliplatin as adjuvant therapy for colon cancer: updated results of NSABP C-07 trial, including survival and subset analyses. J Clin Oncol 2011;29:3768-3774.

11 Saltz LB, Niedzwiecki D, Hollis D, Goldberg RM, Hantel A, Thomas JP, Fields AL, Mayer RJ: Irinotecan fluorouracil plus leucovorin is not superior to fluorouracil plus leucovorin alone as adjuvant treatment for stage III colon cancer: results of CALGB 89803. J Clin Oncol 2007;25:3456-3461.
12 Van Cutsem E, Labianca R, Bodoky G, Barone C, Aranda E, Nordlinger B, Topham C, Tabernero J, André T, Sobrero AF, Mini E, Greil R, Di Costanzo F, Collette L, Cisar L, Zhang X, Khayat D, Bokemeyer C, Roth $\mathrm{AD}$, Cunningham D: Randomized phase III trial comparing biweekly infusional fluorouracil/leucovorin alone or with irinotecan in the adjuvant treatment of stage III colon cancer: PETACC-3. J Clin Oncol 2009; 27:3117-3125.

13 Ychou M, Raoul JL, Douillard JY, Gourgou-Bourgade S, Bugat R, Mineur L, Viret F, Becouarn Y, Bouché O, Gamelin E, Ducreux M, Conroy T, Seitz JF, Bedenne L, Kramar A: A phase III randomised trial of LV5FU2 + irinotecan versus LV5FU2 alone in adjuvant high-risk colon cancer (FNCLCC Accord02/FFCD9802). Ann Oncol 2009;20:674-680.

14 Tikidzhieva A, Benner A, Michel S, Formentini A, Link KH, Dippold W, von Knebel Doeberitz M, Kornmann M, Kloor M: Microsatellite instability and Beta2Microglobulin mutations as prognostic markers in colon cancer: results of the FOGT-4 trial. Br J Cancer 2012;106:1239-1245.

15 Thomaidis T, Maderer A, Formentini A, Bauer S, Trautmann M, Schwarz M, Neumann W, Kittner JM, Schad A, Link KH, Rey JW, Weinmann A, Hoffman A, Galle PR, Kornmann M, Moehler M: Proteins of the VEGFR and EGFR pathway as predictive markers for adjuvant treatment in patients with stage II/III colorectal cancer: results of the FOGT-4 trial. J Exp Clin Cancer Res 2014;33:83.

6 André T, Boni C, Mounedji-Boudiaf L, Navarro M, Tabernero J, Hickish T, Topham C, Zaninelli M, Clingan P, Bridgewater J, Tabah-Fisch I, de Gramont A; Multicenter International Study of Oxaliplatin/5-Fluorouracil/Leucovorin in the Adjuvant Treatment of Colon Cancer (MOSAIC) Investigators: Oxaliplatin, fluorouracil, and leucovorin as adjuvant treatment for colon cancer. N Engl J Med 2004;350:2343-2351.

17 Kolonkarzinom - Interdisziplinäre Leitlinie der Deutschen Krebsgesellschaft und ihrer Arbeitsgemeinschaften, der Deutschen Gesellschaft für Chirurgie und der Deutschen Gesellschaft für Verdauungs- und Stoffwechselkrankheiten. Coloproctology 2000;22: 145-152.

18 Sobin LH, Wittekind C (eds): International Union Against Cancer (UICC). TNM Classification of Malignant Tumors, ed 5. New York, John Wiley \& Sons, Inc., 1997.

19 Pox C, Aretz S, Bischoff SC, Graeven U, et al: S3guideline colorectal cancer version 1.0 (Article in German). Z Gastroenterol 2013;51:753-854.

20 Douillard JY, Cunningham D, Roth AD, Navarro M, James RD, Karasek P, Jandik P, Iveson T, Carmichael J, Alakl M, Gruia G, Awad L, Rougier P: Irinotecan combined with fluorouracil compared with fluorouracil alone as first-line treatment for metastatic colorectal cancer: a multicentre randomised trial. Lancet 2000; 355:1041-1047.
21 Saltz LB, Cox JV, Blanke C, Rosen LS, Fehrenbacher L, Moore MJ, Maroun JA, Ackland SP, Locker PK, Pirotta N, Elfring GL, Miller LL: Irinotecan plus fluorouracil and leucovorin for metastatic colorectal cancer. Irinotecan Study Group. N Engl J Med 2000;343 905-914.

22 De Gramont A, Figer A, Seymour M, Homerin M, Hmissi A, Cassidy J, Boni C, Cortes-Funes H, Cervantes A, Freyer G, Papamichael D, Le Bail N, Louvet C, Hendler D, de Braud F, Wilson C, Morvan F, Bonetti A: Leucovorin and fluorouracil with or without oxaliplatin as first-line treatment in advanced colorectal cancer. J Clin Oncol 2000;18 2938-2947.

23 Kuebler JP, Wieand HS, O’Connell MJ, et al: Oxaliplatin combined with weekly bolus fluorouracil and leucovorin as surgical adjuvant chemotherapy for stage II and III colon cancer: results from NSABP C-7. J Clin Oncol 2007;25:2198-2204.

24 Kornmann M, Formentini A, Ette C, Henne-Bruns D, Kron M, Sander S, Baumann W, Kreuser ED, Staib L, Link KH: Prognostic factors influencing the survival of patients with colon cancer receiving adjuvant 5-FU treatment. Eur J Surg Oncol 2008;34:1316-1321.

25 O'Connell JB, Maggard MA, Ko CY: Colon cancer survival rates with the new American Joint Committee on Cancer sixth edition staging. J Natl Cancer Inst 2004;6 1420-1425.

26 Påhlman LA, Hohenberger WM, Matzel K, Sugihara K, Quirke P, Glimelius B: Should the benefit of adjuvant chemotherapy in colon cancer be re-evaluated? J Clin Oncol 2016;34:1297-1299.

27 Paquet ER, Cui J, Davidson D, Pietrosemoli N, Hassan $\mathrm{HH}$, Tsofack SP, Maltais A, Hallett MT, Delorenzi M Batist G, Aloyz R, Lebel M: A 12-gene signature to distinguish colon cancer patients with better clinical outcome following treatment with 5-fluorouracil or FOLFIRI. J Pathol Clin Res 2015;1:160-172.

8 Lee MS, Menter DG, Kopetz S: Right versus left colon cancer biology: integrating the consensus molecular subtypes. J Natl Compr Canc Netw 2017;15: 411-419.

29 Papadimitriou CA, Papakostas P, Karina M, et al: A randomized phase III trial of adjuvant chemotherapy with irinotecan, leucovorin and fluorouracil versus leucovorin and fluorouracil for stage II and III colon cancer: a Hellenic Cooperative Oncology Group study. BMC Med 2011;9:10.

30 Guinney J, Dienstmann R, Wang X, et al: The consensus molecular subtypes of colorectal cancer. Nat Med 2015;21:1350-1356.

1 Roseweir AK, McMillan DC, Horgan PG, Edwards J: Colorectal cancer subtypes: translation to routine clinical pathology. Cancer Treat Rev 2017;57:1-7.

32 Dienstmann R, Vermeulen L, Guinney J, Kopetz S, Tejpar S, Tabernero J: Consensus molecular subtypes and the evolution of precision medicine in colorectal cancer. Nat Rev Cancer 2017;17:79-92. 